\title{
A LISTING OF THE VOLUMES
}

\section{Published}

by

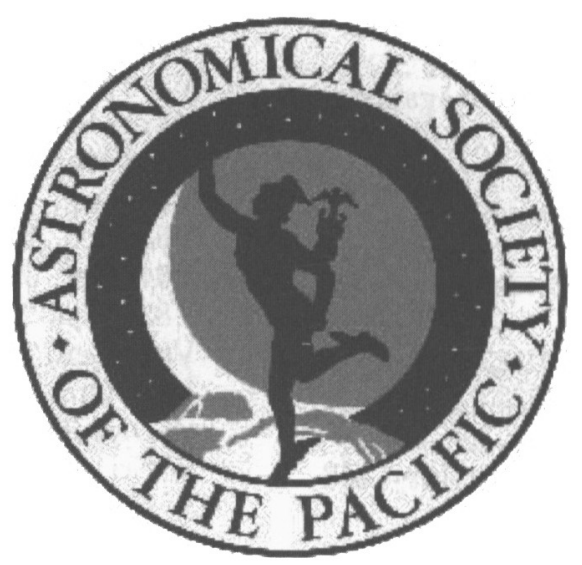

\section{THE ASTRONOMICAL SOCIETY OF THE PACIFIC (ASP)}

An international, nonprofit, scientific and educational organization founded in 1889 


\section{ASTRONOMICAL SOCIETY OF THE PACIFIC CONFERENCE SERIES \\ (ASP - CS)}

and

\section{INTERNATIONAL ASTRONOMICAL UNION VOLUMES (IAU)}

should be directed to the:

\section{Astronomical Society of the Pacific Conference Series 390 Ashton Avenue \\ San Francisco CA 94112-1722 USA}

Phone: 800-335-2624 (within USA)

Phone: 415-337-2126

Fax: 415-337-5205

E-mail: service@astrosociety.org

Web Site: http://www.astrosociety.org

Complete lists of proceedings of past IAU Meetings are maintained at the IAU Web site at the URL: http://www.iau.org/publicat.html

Volumes 32 - 189 in the IAU Symposia Series may be ordered from:

Kluwer Academic Publishers

P. O. Box 117

NL 3300 AA Dordrecht

The Netherlands

Kluwer@wKap.com 


\section{ASP CONFERENCE SERIES VOLUMES}

Published by the Astronomical Society of the Pacific

PUBLISHED: 1988 ( ${ }^{*}$ asterisk means OUT OF STOCK)

Vol. CS -1 PROGRESS AND OPPORTUNITIES IN SOUTHERN HEMISPHERE OPTICAL ASTRONOMY: CTIO $25^{\text {TH }}$ Anniversary Symposium eds. V. M. Blanco and M. M. Phillips ISBN 0-937707-18-X

Vol. CS-2 * PROCEEDINGS OF A WORKSHOP ON OPTICAL SURVEYS FOR QUASARS eds. Patrick S. Osmer, Alain C. Porter, Richard F. Green, and Craig B. Foltz ISBN 0-937707-19-8

Vol. CS-3 * FIBER OPTICS IN ASTRONOMY

ed. Samuel C. Barden

ISBN 0-937707-20-1

Vol. CS-4 THE EXTRAGALACTIC DISTANCE SCALE:

Proceedings of the ASP $100^{\text {th }}$ Anniversary Symposium eds. Sidney van den Bergh and Christopher J. Pritchet ISBN $0-937707-21-X$

Vol. CS-5 * THE MINNESOTA LECTURES ON CLUSTERS OF GALAXIES

AND LARGE-SCALE STRUCTURE

ed. John M. Dickey

ISBN 0-937707-22-8

PUBLISHED: 1989

Vol. CS-6 * SYNTHESIS IMAGING IN RADIO ASTRONOMY: A Collection of Lectures from the Third NRAO Synthesis Imaging Summer School eds. Richard A. Perley, Frederic R. Schwab, and Alan H. Bridle ISBN 0-937707-23-6

PUBLISHED: 1990

Vol. CS-7 PROPERTIES OF HOT LUMINOUS STARS: Boulder-Munich Workshop ed. Catharine D. Garmany

ISBN 0-937707-24-4

Vol. CS-8 * CCDS IN ASTRONOMY

ed. George H. Jacoby

ISBN 0-937707-25-2

Vol. C.S-9 COOL STARS, STELLAR SYSTEMS, AND THE SUN: Sixth Cambridge Workshop ed. George Wallerstein ISBN 0-937707-27-9

Vol. CS-10 * EVOLUTION OF THE UNIVERSE OF GALAXIES:

Edwin Hubble Centennial Symposium

ed. Richard G. Kron

ISBN 0-937707-28-7

Vol. CS-11 CONFRONTATION BETWEEN STELLAR PULSATION AND EVOLUTION eds. Carla Cacciari and Gisella Clementini ISBN 0-937707-30-9

Vol. CS-12 THE EVOLUTION OF THE INTERSTELLAR MEDIUM ed. Leo Blitz

ISBN 0-937707-31-7 


\section{ASP CONFERENCE SERIES VOLUMES}

Published by the Astronomical Society of the Pacific

\section{PUBLISHED: 1991 ( ${ }^{*}$ asterisk means OUT OF STOCK)}

Vol. CS-13

Vol. CS-14

Vol. CS-15

Vol. CS-16

Vol. CS-17

Vol. CS-18

Vol. CS-19 *

Vol. CS-20

Vol. CS-21

PUBLISHED: 1992

Vol. CS-22

Vol CS-23 *

Vol. CS-24

Vol. CS-25

Vol. CS-26
THE FORMATION AND EVOLUTION OF STAR CLUSTERS

ed. Kenneth Janes

ISBN 0-937707-32-5

ASTROPHYSICS WITH INFRARED ARRAYS

ed. Richard Elston

ISBN 0-937707-33-3

LARGE-SCALE STRUCTURES AND PECULIAR MOTIONS IN THE UNIVERSE eds. David W. Latham and L. A. Nicolaci da Costa ISBN 0-937707-34-1

Proceedings of the $3^{\text {rd }}$ Haystack Observatory Conference on ATOMS, IONS, AND MOLECULES: NEW RESULTS IN SPECTRAL LINE ASTROPHYSICS eds. Aubrey D. Haschick and Paul T. P. Ho ISBN 0-937707-35-X

LIGHT POLLUTION, RADIO INTERFERENCE, AND SPACE DEBRIS ed. David L. Crawford ISBN 0-937707-36-8

THE INTERPRETATION OF MODERN SYNTHESIS OBSERVATIONS OF SPIRAL GALAXIES

eds. Nebojsa Duric and Patrick C. Crane

ISBN 0-937707-37-6

RADIO INTERFEROMETRY: THEORY, TECHNIQUES, AND APPLICATIONS,

IAU Colloquium 131

eds. T. J. Cornwell and R. A. Perley

ISBN 0-937707-38-4

FRONTIERS OF STELLAR EVOLUTION:

$50^{\text {th }}$ Anniversary McDonald Observatory (1939-1989)

ed. David L. Lambert

ISBN 0-937707-39-2

THE SPACE DISTRIBUTION OF QUASARS

ed . David Crampton

ISBN 0-937707-40-6

NONISOTROPIC AND VARIABLE OUTFLOWS FROM STARS

eds. Laurent Drissen, Claus Leitherer, and Antonella Nota ISBN 0-937707-41-4

ASTRONOMICAL CCD OBSERVING AND REDUCTION TECHNIQUES ed. Steve B. Howell ISBN 0-937707-42-4

COSMOLOGY AND LARGE-SCALE STRUCTURE IN THE UNIVERSE ed. Reinaldo R. de Carvalho ISBN 0-937707-43-0

ASTRONOMICAL DATA ANALYSIS, SOFTWARE AND SYSTEMS I - (ADASS I) eds. Diana M. Worrall, Chris Biemesderfer, and Jeannette Barnes ISBN 0-937707-44-9

COOL STARS, STELLAR SYSTEMS, AND THE SUN:

Seventh Cambridge Workshop

eds. Mark S. Giampapa and Jay A. Bookbinder

ISBN 0-937707-45-7 
PUBLISHED: 1992 (asterisk means OUT OF STOCK)

Vol. CS-27 THE SOLAR CYCLE: Proceedings of the National Solar Observatory/Sacramento Peak $12^{\text {th }}$ Summer Workshop ed. Karen L. Harvey ISBN 0-937707-46-5

Vol. CS-28 AUTOMATED TELESCOPES FOR PHOTOMETRY AND IMAGING eds. Saul J. Adelman, Robert J. Dukes, Jr., and Carol J. Adelman ISBN 0-937707-47-3

Vol. CS-29 Viña del Mar Workshop on CATACLYSMIC VARIABLE STARS ed. Nikolaus Vogt ISBN 0-937707-48-1

Vol. CS-30 VARIABLE STARS AND GALAXIES

ed. Brian Warner ISBN 0-937707-49-X

Vol. CS-31 RELATIONSHIPS BETWEEN ACTIVE GALACTIC NUCLEI AND STARBURST GALAXIES ed. Alexei V. Filippenko ISBN 0-937707-50-3

Vol. CS-32 COMPLEMENTARY APPROACHES TO DOUBLE AND MULTIPLE STAR RESEARCH, IAU Colloquium 135 eds. Harold A. McAlister and William I. Hartkopf ISBN 0-937707-51-1

Vol. CS-33 * RESEARCH AMATEUR ASTRONOMY ed. Stephen J. Edberg ISBN 0-937707-52-X

Vol. CS-34 ROBOTIC TELESCOPES IN THE 1990's ed. Alexei V. Filippenko ISBN 0-937707-53-8

PUBLISHED: 1993

Vol. CS-35 *

MASSIVE STARS: THEIR LIVES IN THE INTERSTELLAR MEDIUM eds. Joseph P. Cassinelli and Edward B. Churchwell ISBN 0-937707-54-6

Vol. CS-36 PLANETS AROUND PULSARS ed. J. A. Phillips, S. E. Thorsett, and S. R. Kulkarni ISBN 0-937707-55-4

Vol. CS-37 FIBER OPTICS IN ASTRONOMY II ed. Peter M. Gray ISBN 0-937707-56-2

Vol. CS-38 NEW FRONTIERS IN BINARY STAR RESEARCH: Pacific Rim Colloquium eds. K. C. Leung and I.-S. Nha ISBN 0-937707-57-0

Vol. CS-39 THE MINNESOTA LECTURES ON THE STRUCTURE AND DYNAMICS OF THE MILKY WAY ed. Roberta M. Humphreys ISBN 0-937707-58-9 
PUBLISHED: 1993 (" asterisk means OUT OF STOCK)

Vol. CS-40 INSIDE THE STARS, IAU Colloquium 137 eds. Werner W. Weiss and Annie Baglin ISBN 0-937707-59-7

Vol. CS-41 ASTRONOMICAL INFRARED SPECTROSCOPY: FUTURE OBSERVATIONAL DIRECTIONS ed. Sun Kwok ISBN 0-937707-60-0

Vol. CS-42 GONG 1992: SEISMIC INVESTIGATION OF THE SUN AND STARS ed. Timothy M. Brown ISBN 0-937707-61-9

Vol. CS-43 SKY SURVEYS: PROTOSTARS TO PROTOGALAXIES ed. B. T. Soifer ISBN 0-937707-62-7

Vol. CS-44 PECULIAR VERSUS NORMAL PHENOMENA IN A-TYPE AND RELATED STARS, IAU Colloquium 138 eds. M. M. Dworetsky, F. Castelli, and R. Faraggiana ISBN 0-937707-63-5

Vol. CS-45 LUMINOUS HIGH-LATITUDE STARS ed. Dimitar D. Sasselov ISBN 0-937707-64-3

Vol. CS-46 THE MAGNETIC AND VELOCITY FIELDS OF SOLAR ACTIVE REGIONS, IAU Colloquium 141 eds. Harold Zirin, Guoxiang Ai, and Haimin Wang ISBN 0-937707-65-1

Vol. CS-47 THIRD DECENNIAL US-USSR CONFERENCE ON SETI -. Santa Cruz, California, USA ed. G. Seth Shostak ISBN 0-937707-66-X

Vol. CS-48 THE GLOBULAR CLUSTER-GALAXY CONNECTION eds. Graeme H. Smith and Jean P. Brodie ISBN 0-937707-67-8

Vol. CS-49 GALAXY EVOLUTION: THE MILKY WAY PERSPECTIVE ed. Steven R. Majewski ISBN 0-937707-68-6

Vol. CS-50 STRUCTURE AND DYNAMICS OF GLOBULAR CLUSTERS eds. S. G. Djorgovski and G. Meylan ISBN 0-937707-69-4

Vol. CS-51 OBSERVATIONAL COSMOLOGY eds. Guido Chincarini, Angela lovino, Tommaso Maccacaro, and Dario Maccagni ISBN 0-937707-70-8

Vol. CS-52 ASTRONOMICAL DATA ANALYSIS SOFTWARE AND SYSTEMS II - (ADASS II) eds. R. J. Hanisch, R. J. V. Brissenden, and Jeannette Barnes ISBN 0-937707-71-6

Vol. CS-53

BLUE STRAGGLERS ed. Rex A. Saffer ISBN 0-937707-72-4 


\section{PUBLISHED: 1994 (" asterisk means OUT OF STOCK)}

Vol. CS-54 * THE FIRST STROMLO SYMPOSIUM: THE PHYSICS OF ACTIVE GALAXIES eds. Geoffrey V. Bicknell, Michael A. Dopita, and Peter J. Quinn ISBN 0-937707-73-2

Vol. CS-55 OPTICAL ASTRONOMY FROM THE EARTH AND MOON eds. Diane M. Pyper and Ronald J. Angione ISBN 0-937707-74-0

Vol. CS-56 * INTERACTING BINARY STARS ed. Allen W. Shafter ISBN 0-937707-75-9

Vol. CS-57 STELLAR AND CIRCUMSTELLAR ASTROPHYSICS eds. George Wallerstein and Alberto Noriega-Crespo ISBN 0-937707-76-7

Vol. CS-58 * THE FIRST SYMPOSIUM ON THE INFRARED CIRRUS AND DIFFUSE INTERSTELLAR CLOUDS eds. Roc M. Cutri and William B. Latter ISBN 0-937707-77-5

Vol. CS-59 ASTRONOMY WITH MILLIMETER AND SUBMILLIMETER WAVE INTERFEROMETRY, IAU Colloquium 140 eds. M. Ishiguro and Wm. J. Welch ISBN 0-937707-78-3

Vol. CS-60 THE MK PROCESS AT 50 YEARS: A POWERFUL TOOL FOR ASTROPHYSICAL INSIGHT, A Workshop of the Vatican Observatory --Tucson, Arizona, USA eds. C. J. Corbally, R. O. Gray, and R. F. Garrison ISBN 0-937707-79-1

Vol. CS-61 ASTRONOMICAL DATA ANALYSIS SOFTWARE AND SYSTEMS III - (ADASS II) eds. Dennis R. Crabtree, R. J. Hanisch, and Jeannette Barnes ISBN 0-937707-80-5

Vol. CS-62 THE NATURE AND EVOLUTIONARY STATUS OF HERBIG Ae/Be STARS eds. Pik Sin Thé, Mario R. Pérez, and Ed P. J. van den Heuvel ISBN 0-9837707-81-3

Vol. CS-63 SEVENTY-FIVE YEARS OF HIRAYAMA ASTEROID FAMILIES: THE ROLE OF COLLISIONS IN THE SOLAR SYSTEM HISTORY eds. Yoshihide Kozai, Richard P. Binzel, and Tomohiro Hirayama ISBN 0-937707-82-1

Vol. CS-64 * COOL STARS, STELLAR SYSTEMS, AND THE SUN:

Eighth Cambridge Workshop ed. Jean-Pierre Caillault ISBN 0-937707-83-X

Vol. CS-65 * CLOUDS, CORES, AND LOW MASS STARS: The Fourth Haystack Observatory Conference eds. Dan P. Clemens and Richard Barvainis ISBN 0-937707-84-8

Vol. CS-66 * PHYSICS OF THE GASEOUS AND STELLAR DISKS OF THE GALAXY ed. Ivan R. King ISBN 0-937707-85-6 


\title{
ASP CONFERENCE SERIES VOLUMES
}

Published by the Astronomical Society of the Pacific

\section{PUBLISHED: 1994 ( ${ }^{*}$ asterisk means OUT OF STOCK)}

\author{
Vol. CS-67 \\ UNVEILING LARGE-SCALE STRUCTURES BEHIND THE MILKY WAY \\ eds. C. Balkowski and R. C. Kraan-Korteweg \\ ISBN 0-937707-86-4 \\ Vol. CS-68 * SOLAR ACTIVE REGION EVOLUTION: \\ COMPARING MODELS WITH OBSERVATIONS \\ eds. K. S. Balasubramaniam and George W. Simon \\ ISBN 0-937707-87-2 \\ Vol. CS-69 REVERBERATION MAPPING OF THE BROAD-LINE REGION \\ IN ACTIVE GALACTIC NUCLEI \\ eds. P. M. Gondhalekar, K. Horne, and B. M. Peterson \\ ISBN 0-937707-88-0 \\ Vol. CS-70 * GROUPS OF GALAXIES \\ eds. Otto-G. Richter and Kirk Borne \\ ISBN 0-937707-89-9
}

PUBLISHED: 1995

Vol. CS-71 TRIDIMENSIONAL OPTICAL SPECTROSCOPIC METHODS IN ASTROPHYSICS, IAU Colloquium 149 eds. Georges Comte and Michel Marcelin ISBN 0-937707-90-2

Vol. CS-72 MILLISECOND PULSARS: A DECADE OF SURPRISE eds. A. S Fruchter, M. Tavani, and D. C. Backer ISBN 0-937707-91-0

Vol. CS-73 AIRBORNE ASTRONOMY SYMPOSIUM ON THE GALACTIC ECOSYSTEM: FROM GAS TO STARS TO DUST eds. Michael R. Haas, Jacqueline A. Davidson, and Edwin F. Erickson ISBN 0-937707-92-9

Vol. CS-74 PROGRESS IN THE SEARCH FOR EXTRATERRESTRIAL LIFE: 1993 Bioastronomy Symposium ed. G. Seth Shostak ISBN 0-937707-93-7

Vol, CS-75 MULTI-FEED SYSTEMS FOR RADIO TELESCOPES eds. Darrel T. Emerson and John M. Payne ISBN 0-937707-94-5

Vol. CS-76 GONG '94: HELIO-AND ASTERO-SEISMOLOGY FROM THE EARTH AND SPACE eds. Roger K. Ulrich, Edward J. Rhodes, Jr., and Werner Däppen ISBN 0-937707-95-3

Vol. CS-77 ASTRONOMICAL DATA ANALYSIS SOFTWARE AND SYSTEMS IV - (ADASS IV) eds. R. A. Shaw, H. E. Payne, and J. J. E. Hayes ISBN 0-937707-96-1

Vol. CS-78 ASTROPHYSICAL APPLICATIONS OF POWERFUL NEW DATABASES: Joint Discussion No. 16 of the 22nd General Assembly of the IAU eds. S. J. Adelman and W. L. Wiese ISBN 0-937707-97-X 
PUBLISHED: 1995 ( ${ }^{*}$ asterisk means OUT OF STOCK)

Vol. CS-79 * ROBOTIC TELESCOPES: CURRENT CAPABILITIES, PRESENT

DEVELOPMENTS, AND FUTURE PROSPECTS

FOR AUTOMATED ASTRONOMY

eds. Gregory W. Henry and Joel A. Eaton

ISBN 0-937707-98-8

Vol. CS-80 * THE PHYSICS OF THE INTERSTELLAR MEDIUM

AND INTERGALACTIC MEDIUM

eds. A. Ferrara, C. F. McKee, C. Heiles, and P. R. Shapiro

ISBN 0-937707-99-6

Vol. CS-81 LABORATORY AND ASTRONOMICAL HIGH RESOLUTION SPECTRA

eds. A. J. Sauval, R. Blomme, and N. Grevesse

ISBN 1-886733-01-5

Vol. CS-82 * VERY LONG BASELINE INTERFEROMETRY AND THE VLBA

eds. J. A. Zensus, P. J. Diamond, and P. J. Napier

ISBN 1-886733-02-3

Vol. CS-83 * ASTROPHYSICAL APPLICATIONS OF STELLAR PULSATION,

IAU Colloquium 155

eds. R. S. Stobie and P. A. Whitelock

ISBN 1-886733-03-1

ATLAS

INFRARED ATLAS OF THE ARCTURUS SPECTRUM, 0.9 - $5.3 \mu \mathrm{m}$ eds. Kenneth Hinkle, Lloyd Wallace, and William Livingston

ISBN: 1-886733-04-X

Vol. CS-84 THE FUTURE UTILIZATION OF SCHMIDT TELESCOPES, IAU Colloquium 148 eds. Jessica Chapman, Russell Cannon, Sandra Harrison, and Bambang Hidayat ISBN 1-886733-05-8

Vol. CS-85 * CAPE WORKSHOP ON MAGNETIC CATACLYSMIC VARIABLES

eds. D. A. H. Buckley and B. Warner

ISBN 1-886733-06-6

Vol. CS-86 FRESH VIEWS OF ELLIPTICAL GALAXIES

eds. Alberto Buzzoni, Alvio Renzini, and Alfonso Serrano

ISBN 1-886733-07-4

PUBLISHED: 1996

Vol. CS-87 NEW OBSERVING MODES FOR THE NEXT CENTURY eds. Todd Boroson, John Davies, and lan Robson ISBN 1-886733-08-2

Vol. CS-88 * CLUSTERS, LENSING, AND THE FUTURE OF THE UNIVERSE eds. Virginia Trimble and Andreas Reisenegger ISBN 1-886733-09-0

Vol. CS-89 ASTRONOMY EDUCATION: CURRENT DEVELOPMENTS, FUTURE COORDINATION ed. John R. Percy ISBN 1-886733-10-4

Vol. CS-90 THE ORIGINS, EVOLUTION, AND DESTINIES OF BINARY STARS IN CLUSTERS

eds. E. F. Milone and J. -C. Mermilliod

ISBN 1-886733-11-2 


\section{PUBLISHED: 1996 (* asterisk means OUT OF STOCK)}

Vol. CS-91 BARRED GALAXIES, IAU Colloquium 157 eds. R. Buta, D. A. Crocker, and B. G. Elmegreen ISBN 1-886733-12-0

Vol. CS-92 * FORMATION OF THE GALACTIC HALO .... INSIDE AND OUT eds. Heather L. Morrison and Ata Sarajedini ISBN 1-886733-13-9

Vol. CS-93 RADIO EMISSION FROM THE STARS AND THE SUN eds. A. R. Taylor and J. M. Paredes ISBN 1-886733-14-7

Vol. CS-94 MAPPING, MEASURING, AND MODELING THE UNIVERSE eds. Peter Coles, Vicent J. Martinez, and Maria-Jesus Pons-Borderia ISBN 1-886733-15-5

Vol. CS-95 SOLAR DRIVERS OF INTERPLANETARY AND TERRESTRIAL DISTURBANCES: Proceedings of $16^{\text {th }}$ International Workshop National Solar Observatory/Sacramento Peak eds. K. S. Balasubramaniam, Stephen L. Keil, and Raymond N. Smartt ISBN 1-886733-16-3

Vol. CS-96 HYDROGEN-DEFICIENT STARS eds. C. S. Jeffery and U. Heber ISBN 1-886733-17-1

Vol. CS-97 POLARIMETRY OF THE INTERSTELLAR MEDIUM eds. W. G. Roberge and D. C. B. Whittet ISBN 1-886733-18-X

Vol. CS-98 FROM STARS TO GALAXIES: THE IMPACT OF STELLAR PHYSICS ON GALAXY EVOLUTION

eds. Claus Leitherer, Uta Fritze-von Alvensleben, and John Huchra ISBN 1-886733-19-8

Vol. CS-99 COSMIC ABUNDANCES:

Proceedings of the 6th Annual October Astrophysics Conference eds. Stephen S. Holt and George Sonneborn ISBN 1-886733-20-1

Vol. CS-100 ENERGY TRANSPORT IN RADIO GALAXIES AND QUASARS eds. P. E. Hardee, A. H. Bridle, and J. A. Zensus ISBN 1-886733-21-X

Vol. CS-101 ASTRONOMICAL DATA ANALYSIS SOFTWARE AND SYSTEMS V - (ADASS V) eds. George H. Jacoby and Jeannette Barnes ISBN 1080-7926

Vol. CS-102 THE GALACTIC CENTER, 4th ESO/CTIO Workshop ed. Roland Gredel ISBN 1-886733-22-8

Vol. CS-103 THE PHYSICS OF LINERS IN VIEW OF RECENT OBSERVATIONS eds. M. Eracleous, A. Koratkar, C. Leitherer, and L. Ho ISBN 1-886733-23-6 


\section{PUBLISHED: 1996 (* asterisk means OUT OF STOCK)}

Vol. CS-104* PHYSICS, CHEMISTRY, AND DYNAMICS OF INTERPLANETARY DUST, IAU Colloquium 150

eds. Bo A. S. Gustafson and Martha S. Hanner

ISBN 1-886733-24-4

Vol. CS-105 PULSARS: PROBLEMS AND PROGRESS, IAU Colloquium 160 ed. S. Johnston, M. A. Walker, and M. Bailes ISBN 1-886733-25-2

Vol. CS-106 THE MINNESOTA LECTURES ON EXTRAGALACTIC NEUTRAL HYDROGEN ed. Evan D. Skillman ISBN 1-886733-26-0

Vol. CS-107 COMPLETING THE INVENTORY OF THE SOLAR SYSTEM:

A Symposium held in conjunction with the 106th Annual Meeting of the ASP eds. Terrence W. Rettig and Joseph M. Hahn ISBN 1-886733-27-9

Vol. CS-108 M.A.S.S. -- MODEL ATMOSPHERES AND SPECTRUM SYNTHESIS: 5th Vienna - Workshop eds. Saul J. Adelman, Friedrich Kupka, and Werner W. Weiss ISBN 1-886733-28-7

Vol. CS-109 COOL STARS, STELLAR SYSTEMS, AND THE SUN: Ninth Cambridge Workshop eds. Roberto Pallavicini and Andrea K. Dupree ISBN 1-886733-29-5

Vol. CS-110 BLAZAR CONTINUUM VARIABILITY eds. H. R. Miller, J. R. Webb, and J. C. Noble ISBN 1-886733-30-9

Vol. CS-111 MAGNETIC RECONNECTION IN THE SOLAR ATMOSPHERE: Proceedings of a Yohkoh Conference eds. R. D. Bentley and J. T. Mariska ISBN 1-886733-31-7

Vol. CS-112 THE HISTORY OF THE MILKY WAY AND ITS SATELLITE SYSTEM eds. Andreas Burkert, Dieter H. Hartmann, and Steven R. Majewski ISBN 1-886733-32-5

PUBLISHED: 1997

Vol. CS-113 EMISSION LINES IN ACTIVE GALAXIES: NEW METHODS AND TECHNIQUES, IAU Colloquium 159 eds. B. M. Peterson, F.-Z. Cheng, and A. S. Wilson ISBN 1-886733-33-3

Vol. CS-114 YOUNG GALAXIES AND QSO ABSORPTION-LINE SYSTEMS eds. Sueli M. Viegas, Ruth Gruenwald, and Reinaldo R. de Carvalho ISBN 1-886733-34-1

Vol. CS-115 GALACTIC CLUSTER COOLING FLOWS ed. Noam Soker ISBN 1-886733-35-X 


\section{ASP CONFERENCE SERIES VOLUMES}

Published by the Astronomical Society of the Pacific

PUBLISHED: 1997 ( ${ }^{*}$ asterisk means OUT OF STOCK)

Vol. CS-116 THE SECOND STROMLO SYMPOSIUM: THE NATURE OF ELLIPTICAL GALAXIES eds. M. Arnaboldi, G. S. Da Costa, and P. Saha ISBN 1-886733-36-8

Vol. CS-117 DARK AND VISIBLE MATTER IN GALAXIES eds. Massimo Persic and Paolo Salucci ISBN-1-886733-37-6

Vol. CS-118 FIRST ADVANCES IN SOLAR PHYSICS EUROCONFERENCE: ADVANCES IN THE PHYSICS OF SUNSPOTS eds. B. Schmieder. J. C. del Toro Iniesta, and M. Vázquez ISBN 1-886733-38-4

Vol. CS-119 PLANETS BEYOND THE SOLAR SYSTEM AND THE NEXT GENERATION OF SPACE MISSIONS ed. David R. Soderblom ISBN 1-886733-39-2

Vol. CS-120 LUMINOUS BLUE VARIABLES: MASSIVE STARS IN TRANSITION eds. Antonella Nota and Henny J. G. L. M. Lamers ISBN 1-886733-40-6

Vol. CS-121

ACCRETION PHENOMENA AND RELATED OUTFLOWS, IAU Colloquium 163 eds. D. T. Wickramasinghe, G. V. Bicknell, and L. Ferrario ISBN 1-886733-41-4

Vol. CS-122 FROM STARDUST TO PLANETESIMALS:

Symposium held as part of the 108th Annual Meeting of the ASP eds. Yvonne J. Pendleton and A. G. G. M. Tielens ISBN 1-886733-42-2

Vol. CS-123

Vol. CS-124

THE $12^{\text {th }}$ 'KINGSTON MEETING': COMPUTATIONAL ASTROPHYSICS eds. David A. Clarke and Michael J. West ISBN 1-886733-43-0

DIFFUSE INFRARED RADIATION AND THE IRTS eds. Haruyuki Okuda, Toshio Matsumoto, and Thomas Roellig ISBN 1-886733-44-9

Vol. CS-125

ASTRONOMICAL DATA ANALYSIS SOFTWARE AND SYSTEMS VI eds. Gareth Hunt and H. E. Payne ISBN 1-886733-45-7

Vol. CS-126 FROM QUANTUM FLUCTUATIONS TO COSMOLOGICAL STRUCTURES eds. David Valls-Gabaud, Martin A. Hendry, Paolo Molaro, and Khalil Chamcham ISBN 1-886733-46-5

Vol. CS-127

PROPER MOTIONS AND GALACTIC ASTRONOMY ed. Roberta M. Humphreys ISBN 1-886733-47-3

Vol. CS-128 MASS EJECTION FROM AGN (Active Galactic Nuclei) eds. N. Arav, I. Shlosman, and R. J. Weymann ISBN 1-886733-48-1

Vol. CS-129

THE GEORGE GAMOW SYMPOSIUM eds. E. Harper, W. C. Parke, and G. D. Anderson ISBN 1-886733-49-X 
PUBLISHED: 1997 ( ${ }^{*}$ asterisk means OUT OF STOCK)

Vol. CS-130 THE THIRD PACIFIC RIM CONFERENCE ON RECENT DEVELOPMENT ON BINARY STAR RESEARCH eds. Kam-Ching Leung ISBN 1-886733-50-3

PUBLISHED: 1998

Vol. CS-131

Vol. CS-132

Vol. CS-133

Vol. CS-134 *

Vol. CS-135

Vol. CS-136

Vol. CS-137

Vol. CS-138

Vol. CS-139

Vol. CS-140

Vol. CS-141

Vol. CS-142
BOULDER-MUNICH II: PROPERTIES OF HOT, LUMINOUS STARS ed. Ian D. Howarth ISBN 1-886733-51-1

STAR FORMATION WITH THE INFRARED SPACE OBSERVATORY (ISO) eds. João L. Yun and René Liseau ISBN 1-886733-52-X

SCIENCE WITH THE NGST (Next Generation Space Telescope) eds. Eric P. Smith and Anuradha Koratkar ISBN 1-886733-53-8

BROWN DWARFS AND EXTRASOLAR PLANETS eds. Rafael Rebolo, Eduardo L. Martin, and Maria Rosa Zapatero Osorio ISBN 1-886733-54-6

A HALF CENTURY OF STELLAR PULSATION INTERPRETATIONS: A TRIBUTE TO ARTHUR N. COX eds. P. A. Bradley and J. A. Guzik ISBN 1-886733-55-4

GALACTIC HALOS: A UC SANTA CRUZ WORKSHOP ed. Dennis Zaritsky

ISBN 1-886733-56-2

WILD STARS IN THE OLD WEST: PROCEEDINGS OF THE $13^{\text {th }}$ NORTH AMERICAN WORKSHOP ON CATACLYSMIC VARIABLES AND RELATED OBJECTS eds. S. Howell, E. Kuulkers, and C. Woodward ISBN 1-886733-57-0

1997 PACIFIC RIM CONFERENCE ON STELLAR ASTROPHYSICS eds. Kwing Lam Chan, K. S. Cheng, and H. P. Singh ISBN 1-886733-58-9

PRESERVING THE ASTRONOMICAL WINDOWS:

Proceedings of Joint Discussion No. 5 of the 23rd General Assembly of the IAU eds. Syuzo isobe and Tomohiro Hirayama ISBN 1-886733-59-7

SYNOPTIC SOLAR PHYSICS --18th NSO/Sacramento Peak Summer Workshop eds. K. S. Balasubramaniam, J. W. Harvey, and D. M. Rabin ISBN 1-886733-60-0

ASTROPHYSICS FROM ANTARCTICA: A Symposium held as a part of the $109^{\text {th }}$ Annual Meeting of the ASP eds. Giles Novak and Randall H. Landsberg ISBN 1-886733-61-9

THE STELLAR INITIAL MASS FUNCTION: 38th Herstmonceux Conference eds. Gerry Gilmore and Debbie Howell ISBN 1-886733-62-7 


\section{ASP CONFERENCE SERIES VOLUMES}

Published by the Astronomical Society of the Pacific

PUBLISHED: 1998 ( ${ }^{*}$ asterisk means OUT OF STOCK)

Vol. CS-143 * THE SCIENTIFIC IMPACT OF THE GODDARD HIGH RESOLUTION SPECTROGRAPH (GHRS)

eds. John C. Brandt, Thomas B. Ake III, and Carolyn Collins Petersen ISBN 1-886733-63-5

Vol. CS-144 RADIO EMISSION FROM GALACTIC AND EXTRAGALACTIC COMPACT SOURCES, IAU Colloquium 164 eds. J. Anton Zensus, G. B. Taylor, and J. M. Wrobel ISBN 1-886733-64-3

Vol. CS-145 ASTRONOMICAL DATA ANALYSIS SOFTWARE AND SYSTEMS VII - (ADASS VII) eds. Rudolf Albrecht, Richard N. Hook, and Howard A. Bushouse ISBN 1-886733-65-1

Vol. CS-146 THE YOUNG UNIVERSE GALAXY FORMATION AND EVOLUTION AT INTERMEDIATE AND HIGH REDSHIFT eds. S. D'Odorico, A. Fontana, and E. Giallongo ISBN 1-886733-66-X

Vol. CS-147 ABUNDANCE PROFILES: DIAGNOSTIC TOOLS FOR GALAXY HISTORY eds. Daniel Friedli, Mike Edmunds, Carmelle Robert, and Laurent Drissen ISBN 1-886733-67-8

Vol. CS-148 ORIGINS

eds. Charles E. Woodward, J. Michael Shull, and Harley A. Thronson, Jr. ISBN 1-886733-68-6

Vol. CS-149 SOLAR SYSTEM FORMATION AND EVOLUTION eds. D. Lazzaro, R. Vieira Martins, S. Ferraz-Mello, J. Fernández, and C. Beaugé ISBN 1-886733-69-4

Vol. CS-150 NEW PERSPECTIVES ON SOLAR PROMINENCES, IAU Colloquium 167 eds. David Webb, David Rust, and Brigitte Schmieder ISBN 1-886733-70-8

Vol. CS-151 COSMIC MICROWAVE BACKGROUND AND LARGE SCALE STRUCTURES OF THE UNIVERSE eds. Yong-lk Byun and Kin-Wang $\mathrm{Ng}$ ISBN 1-886733-71-6

Vol. CS-152 FIBER OPTICS IN ASTRONOMY III eds. S. Arribas, E. Mediavilla, and F. Watson ISBN 1-886733-72-4

Vol. CS-153 LIBRARY AND INFORMATION SERVICES IN ASTRONOMY III - (LISA III) eds. Uta Grothkopf, Heinz Andernach, Sarah Stevens-Rayburn, and Monique Gomez ISBN 1-886733-73-2

Vol. CS-154 COOL STARS, STELLAR SYSTEMS AND THE SUN: Tenth Cambridge Workshop eds. Robert A. Donahue and Jay A. Bookbinder ISBN 1-886733-74-0

Vol. CS-155 SECOND ADVANCES IN SOLAR PHYSICS EUROCONFERENCE: THREE-DIMENSIONAL STRUCTURE OF SOLAR ACTIVE REGIONS eds. Costas E. Alissandrakis and Brigitte Schmieder ISBN 1-886733-75-9 


\section{PUBLISHED: 1999 (" asterisk means OUT OF STOCK)}

Vol. CS-156 HIGHLY REDSHIFTED RADIO LINES eds. C. L. Carilli, S. J. E. Radford, K. M. Menten, and G. I. Langston ISBN 1-886733-76-7

Vol. CS-157 ANNAPOLIS WORKSHOP ON MAGNETIC CATACLYSMIC VARIABLES eds. Coel Hellier and Koji Mukai ISBN 1-886733-77-5

Vol. CS-158 SOLAR AND STELLAR ACTIVITY: SIMILARITIES AND DIFFERENCES eds. C. J. Butler and J. G. Doyle ISBN 1-886733-78-3

Vol. CS-159

BL LAC PHENOMENON

eds. Leo $O$. Takalo and Aimo Sillanpää ISBN 1-886733-79-1

Vol. CS-160

ASTROPHYSICAL DISCS: An EC Summer School eds. J. A. Sellwood and Jeremy Goodman ISBN 1-886733-80-5

Vol. CS-161 HIGH ENERGY PROCESSES IN ACCRETING BLACK HOLES eds. Juri Poutanen and Roland Svensson ISBN 1-886733-81-3

Vol. CS-162

QUASARS AND COSMOLOGY

eds. Gary Ferland and Jack Baldwin ISBN 1-886733-83-X

Vol. CS-163

STAR FORMATION IN EARLY-TYPE GALAXIES

eds. Jordi Cepa and Patricia Carral

ISBN 1-886733-84-8

Vol. CS-164

ULTRAVIOLET-OPTICAL SPACE ASTRONOMY BEYOND HST eds. Jon A. Morse, J. Michael Shull, and Anne L. Kinney ISBN 1-886733-85-6

Vol. CS-165 THE THIRD STROMLO SYMPOSIUM: THE GALACTIC HALO eds. Brad K. Gibson, Tim S. Axelrod, and Mary E. Putman ISBN 1-886733-86-4

Vol. CS-166

STROMLO WORKSHOP ON HIGH-VELOCITY CLOUDS eds. Brad K. Gibson and Mary E. Putman ISBN 1-886733-87-2

Vol. CS-167 HARMONIZING COSMIC DISTANCE SCALES IN A POST-HIPPARCOS ERA eds. Daniel Egret and André Heck ISBN 1-886733-88-0

Vol. CS-168 NEW PERSPECTIVES ON THE INTERSTELLAR MEDIUM eds. A. R. Taylor, T. L. Landecker, and G. Joncas ISBN 1-886733-89-9

Vol. CS-169 $11^{\text {th }}$ EUROPEAN WORKSHOP ON WHITE DWARFS eds. J.-E. Solheim and E. G. Meištas ISBN 1-886733-91-0

Vol. CS-170 THE LOW SURFACE BRIGHTNESS UNIVERSE, IAU Colloquium 171 eds. J. I. Davies, C. Impey, and S. Phillipps ISBN 1-886733-92-9 
PUBLISHED: 1999 (* asterisk means OUT OF STOCK)

Vol. CS-171 LiBeB, COSMIC RAYS, AND RELATED X-AND GAMMA-RAYS eds. Reuven Ramaty, Elisabeth Vangioni-Flam, Michel Cassé, and Keith Olive ISBN 1-886733-93-7

Vol. CS-172 ASTRONOMICAL DATA ANALYSIS SOFTWARE AND SYSTEMS VIII eds. David M. Mehringer, Raymond L. Plante, and Douglas A. Roberts ISBN 1-886733-94-5

Vol. CS-173 THEORY AND TESTS OF CONVECTION IN STELLAR STRUCTURE: First Granada Workshop ed. Alvaro Giménez, Edward F. Guinan, and Benjamín Montesinos ISBN 1-886733-95-3

Vol. CS-174 CATCHING THE PERFECT WAVE: ADAPTIVE OPTICS AND INTERFEROMETRY IN THE $21^{\text {st }}$ CENTURY, A Symposium held as a part of the $110^{\text {th }}$ Annual Meeting of the ASP eds. Sergio R. Restaino, William Junor, and Nebojsa Duric ISBN 1-886733-96-1

Vol. CS-175 STRUCTURE AND KINEMATICS OF QUASAR BROAD LINE REGIONS eds. C. M. Gaskell, W. N. Brandt, M. Dietrich, D. Dultzin-Hacyan, and $M$. Eracleous ISBN 1-886733-97-X

Vol. CS-176 OBSERVATIONAL COSMOLOGY: THE DEVELOPMENT OF GALAXY SYSTEMS eds. Giuliano Giuricin, Marino Mezzetti, and Paolo Salucci ISBN 1-58381-000-5

Vol. CS-177 ASTROPHYSICS WITH INFRARED SURVEYS: A Prelude to SIRTF eds. Michael D. Bicay, Chas A. Beichman, Roc M. Cutri, and Barry F. Madore ISBN 1-58381-001-3

Vol. CS-178 STELLAR DYNAMOS: NONLINEARITY AND CHAOTIC FLOWS eds. Manuel Núñez and Antonio Ferriz-Mas ISBN 1-58381-002-1

Vol. CS-179 ETA CARINAE AT THE MILLENNIUM eds. Jon A. Morse, Roberta M. Humphreys, and Augusto Damineli ISBN 1-58381-003-X

Vol. CS-180 SYNTHESIS IMAGING IN RADIO ASTRONOMY || eds. G. B. Taylor, C. L. Carilli, and R. A. Perley ISBN 1-58381-005-6

Vol. CS-181 MICROWAVE FOREGROUNDS

eds. Angelica de Oliveira-Costa and Max Tegmark ISBN 1-58381-006-4

Vol. CS-182 GALAXY DYNAMICS: A Rutgers Symposium eds. David Merritt, J. A. Sellwood, and Monica Valluri ISBN 1-58381-007-2

Vol. CS-183 HIGH RESOLUTION SOLAR PHYSICS: THEORY, OBSERVATIONS, AND TECHNIQUES

eds. T. R. Rimmele, K. S. Balasubramaniam, and R. R. Radick ISBN 1-58381-009-9 


\section{PUBLISHED: 1999 (* asterisk means OUT OF STOCK)}

Vol. CS-184 THIRD ADVANCES IN SOLAR PHYSICS EUROCONFERENCE: MAGNETIC FIELDS AND OSCILLATIONS eds. B. Schmieder, A. Hofmann, and J. Staude ISBN $1-58381-010-2$

Vol. CS-185 PRECISE STELLAR RADIAL VELOCITIES, IAU Colloquium 170 eds. J. B. Hearnshaw and C. D. Scarfe ISBN 1-58381-011-0

Vol. CS-186 THE CENTRAL PARSECS OF THE GALAXY eds. Heino Falcke, Angela Cotera, Wolfgang J. Duschl, Fulvio Melia, and Marcia J. Rieke ISBN 1-58381-012-9

Vol. CS-187 THE EVOLUTION OF GALAXIES ON COSMOLOGICAL TIMESCALES eds. J. E. Beckman and T. J. Mahoney ISBN 1-58381-013-7

Vol. CS-188 OPTICAL AND INFRARED SPECTROSCOPY OF CIRCUMSTELLAR MATTER eds. Eike W. Guenther, Bringfried Stecklum, and Sylvio Klose ISBN 1-58381-014-5

Vol. CS-189 CCD PRECISION PHOTOMETRY WORKSHOP eds. Eric R. Craine, Roy A. Tucker, and Jeannette Bames ISBN 1-58381-015-3

Vol. CS-190

GAMMA-RAY BURSTS: THE FIRST THREE MINUTES eds. Juri Poutanen and Roland Svensson ISBN 1-58381-016-1

Vol. CS-191 PHOTOMETRIC REDSHIFTS AND HIGH REDSHIFT GALAXIES eds. Ray J. Weymann, Lisa J. Storrie-Lombardi, Marcin Sawicki, and Robert J. Brunner ISBN 1-58381-017-X

Vol. CS-192 SPECTROPHOTOMETRIC DATING OF STARS AND GALAXIES ed. I. Hubeny, S. R. Heap, and R. H. Cornett ISBN 1-58381-018-8

Vol. CS-193 THE HY-REDSHIFT UNIVERSE:

GALAXY FORMATION AND EVOLUTION AT HIGH REDSHIFT eds. Andrew J. Bunker and Wil J. M. van Breugel ISBN 1-58381-019-6

Vol. CS-194 WORKING ON THE FRINGE: OPTICAL AND IR INTERFEROMETRY FROM GROUND AND SPACE eds. Stephen Unwin and Robert Stachnik ISBN 1-58381-020-X

PUBLISHED: 2000

Vol. CS-195 IMAGING THE UNIVERSE IN THREE DIMENSIONS: Astrophysics with Advanced Multi-Wavelength Imaging Devices eds. W. van Breugel and J. Bland-Hawthorn ISBN 1-58381-022-6 
PUBLISHED: 2000 ( ${ }^{*}$ asterisk means OUT OF STOCK)

Vol. CS-196 THERMAL EMISSION SPECTROSCOPY AND ANALYSIS OF DUST, DISKS, AND REGOLITHS

eds. Michael L. Sitko, Ann L. Sprague, and David K. Lynch

ISBN: 1-58381-023-4

Vol. CS-197 XV $\quad \mathrm{XV}^{\mathrm{n}}$ IAP MEETING DYNAMICS OF GALAXIES:

FROM THE EARLY UNIVERSE TO THE PRESENT

eds. F. Combes, G. A. Mamon, and V. Charmandaris

ISBN: $1-58381-24-2$

Vol. CS-198 EUROCONFERENCE ON “STELLAR CLUSTERS AND ASSOCIATIONS:

CONVECTION, ROTATION, AND DYNAMOS"

eds. R. Pallavicini, G. Micela, and S. Sciortino

ISBN: $1-58381-25-0$

Vol. CS-199 ASYMMETRICAL PLANETARY NEBULAE ॥:

FROM ORIGINS TO MICROSTRUCTURES

eds. J. H. Kastner, N. Soker, and S. Rappaport

ISBN: $1-58381-026-9$

Vol. CS-200 CLUSTERING AT HIGH REDSHIFT

eds. A. Mazure, O. Le Févre, and V. Le Brun

ISBN: $1-58381-027-7$

Vol. CS-201 COSMIC FLOWS 1999: TOWARDS AN UNDERSTANDING

OF LARGE-SCALE STRUCTURES

eds. Stéphane Courteau, Michael A. Strauss, and Jeffrey A. Willick

ISBN: 1-58381-028-5

Vol. CS-202 * PULSAR ASTRONOMY - 2000 AND BEYOND, IAU Colloquium 177

eds. M. Kramer, N. Wex, and R. Wielebinski

ISBN: 1-58381-029-3

Vol. CS-203 THE IMPACT OF LARGE-SCALE SURVEYS ON PULSATING STAR RESEARCH, IAU Colloquium 176

eds. L. Szabados and D. W. Kurtz

ISBN: $1-58381-030-7$

Vol. CS-204 THERMAL AND IONIZATION ASPECTS OF FLOWS FROM HOT STARS: OBSERVATIONS AND THEORY

eds. Henny J. G. L. M. Lamers and Arved Sapar

ISBN: $1-58381-031-5$

Vol. CS-205 THE LAST TOTAL SOLAR ECLIPSE OF THE MILLENNIUM IN TURKEY eds. W. C. Livingston and A. Özgüç

ISBN: 1-58381-032-3

Vol. CS-206 HIGH ENERGY SOLAR PHYSICS - ANTICIPATING HESSI

eds. Reuven Ramaty and Natalie Mandzhavidze

ISBN: 1-58381-033-1

Vol. CS-207 NGST SCIENCE AND TECHNOLOGY EXPOSITION

eds. Eric P. Smith and Knox S. Long

ISBN: $1-58381-036-6$

ATLAS VISIBLE AND NEAR INFRARED ATLAS OF THE ARCTURUS SPECTRUM $3727-9300 \AA$

eds. Kenneth Hinkle, Lloyd Wallace, Jeff Valenti, and Dianne Harmer ISBN: 1-58381-037-4 


\section{PUBLISHED: 2000 ( ${ }^{\star}$ asterisk means OUT OF STOCK)}

VOI. CS-208 POLAR MOTION: HISTORICAL AND SCIENTIFIC PROBLEMS, IAU Colloquium 178 eds. Steven Dick, Dennis McCarthy, and Brian Luzum ISBN: $1-58381-039-0$

Vol. CS-209 SMALL GALAXY GROUPS, IAU Colloquium 174 eds. Mauri J. Valtonen and Chris Flynn ISBN: 1-58381-040-4

Vol. CS-210 DELTA SCUTI AND RELATED STARS: Reference Handbook and Proceedings of the $6^{\text {th }}$ Vienna Workshop in Astrophysics eds. Michel Breger and Michael Houston Montgomery ISBN: 1-58381-043-9

Vol. CS-211 MASSIVE STELLAR CLUSTERS eds. Ariane Lançon and Christian M. Boily ISBN: 1-58381-042-0

Vol. CS-212 FROM GIANT PLANETS TO COOL STARS eds. Caitlin A. Griffith and Mark S. Marley ISBN: 1-58381-041-2

Vol. CS-213 BIOASTRONOMY '99: A NEW ERA IN BIOASTRONOMY eds. Guillermo A. Lemarchand and Karen J. Meech ISBN: 1-58381-044-7

Vol. CS-214 THE Be PHENOMENON IN EARLY-TYPE STARS, IAU Colloquium 175 eds. Myron A. Smith, Huib F. Henrichs and Juan Fabregat ISBN: 1-58381-045-5

Vol. CS-215 COSMIC EVOLUTION AND GALAXY FORMATION: STRUCTURE, INTERACTIONS AND FEEDBACK The $3^{\text {rd }}$ Guillermo Haro Astrophysics Conference eds. José Franco, Elena Terlevich, Omar López-Cruz, and Itziar Aretxaga ISBN: 1-58381-046-3

Vol. CS-216 ASTRONOMICAL DATA ANALYSIS SOFTWARE AND SYSTEMS IX eds. Nadine Manset, Christian Veillet, and Dennis Crabtree ISBN: 1-58381-047-1 ISSN: $1080-7926$

Vol. CS-217 IMAGING AT RADIO THROUGH SUBMILLIMETER WAVELENGTHS eds. Jeffrey G. Mangum and Simon J. E. Radford ISBN: $1-58381-049-8$

Vol. CS-218 MAPPING THE HIDDEN UNIVERSE: THE UNIVERSE BEHIND THE MILKY WAY THE UNIVERSE IN HI eds. Renée C. Kraan-Korteweg, Patricia A. Henning, and Heinz Andernach ISBN: 1-58381-050-1

Vol. CS-219 DISKS, PLANETESIMALS, AND PLANETS

eds. F. Garzón, C. Eiroa, D. de Winter, and T. J. Mahoney ISBN: $1-58381-051-X$

VOI. CS-220 AMATEUR - PROFESSIONAL PARTNERSHIPS IN ASTRONOMY: The $111^{\text {th }}$ Annual Meeting of the ASP eds. John R. Percy and Joseph B. Wilson ISBN: 1-58381-052-8 
PUBLISHED: 2000 ( ${ }^{*}$ asterisk means OUT OF STOCK)

Vol. CS-221 STARS, GAS AND DUST IN GALAXIES: EXPLORING THE LINKS eds. Danielle Alloin, Knut Olsen, and Gaspar Galaz ISBN: $1-58381-053-6$

PUBLISHED: 2001

Vol. CS-222 THE PHYSICS OF GALAXY FORMATION eds. M. Umemura and $\mathrm{H}$. Susa ISBN: 1-58381-054-4

Vol. CS-223 COOL STARS, STELLAR SYSTEMS AND THE SUN: Eleventh Cambridge Workshop eds. Ramón J. Garcia López, Rafael Rebolo, and María Zapatero Osorio ISBN: 1-58381-056-0

Vol. CS-224 PROBING THE PHYSICS OF ACTIVE GALACTIC NUCLEI BY MULTIWAVELENGTH MONITORING eds. Bradley M. Peterson, Ronald S. Polidan, and Richard W. Pogge ISBN: 1-58381-055-2

Vol. CS-225 VIRTUAL OBSERVATORIES OF THE FUTURE eds. Robert J. Brunner, S. George Djorgovski, and Alex S. Szalay ISBN: 1-58381-057-9

Vol. CS-226 $12^{\text {th }}$ EUROPEAN CONFERENCE ON WHITE DWARFS eds. J. L. Provencal, H. L. Shipman, J. MacDonald, and S. Goodchild ISBN: 1-58381-058-7

Vol. CS-227 BLAZAR DEMOGRAPHICS AND PHYSICS eds. Paolo Padovani and C. Megan Urry ISBN: 1-58381-059-5

Vol. CS-228 DYNAMICS OF STAR CLUSTERS AND THE MILKY WAY eds. S. Deiters, B. Fuchs, A. Just, R. Spurzem, and R. Wielen ISBN: 1-58381-060-9

Vol. CS-229 EVOLUTION OF BINARY AND MULTIPLE STAR SYSTEMS A Meeting in Celebration of Peter Eggleton's $60^{\text {th }}$ Birthday eds. Ph. Podsiadlowski, S. Rappaport, A. R. King, F. D'Antona, and L. Burderi IBSN: 1-58381-061-7

Vol. CS-230 GALAXY DISKS AND DISK GALAXIES eds. Jose G. Funes, S. J. and Enrico Maria Corsini ISBN: 1-58381-063-3

Vol. CS-231 TETONS 4: GALACTIC STRUCTURE, STARS, AND THE INTERSTELLAR MEDIUM eds. Charles E. Woodward, Michael D. Bicay, and J. Michael Shull ISBN: 1-58381-064-1

Vol. CS-232 THE NEW ERA OF WIDE FIELD ASTRONOMY eds. Roger Clowes, Andrew Adamson, and Gordon Bromage ISBN: 1-58381-065-X

Vol. CS-233 P CYGNI 2000: 400 YEARS OF PROGRESS eds. Mart de Groot and Christiaan Sterken ISBN: 1-58381-070-6 


\section{ASP CONFERENCE SERIES VOLUMES}

Published by the Astronomical Society of the Pacific

\section{PUBLISHED: 2001 ( ${ }^{*}$ asterisk means OUT OF STOCK)}

Vol. CS-234 X-RAY ASTRONOMY 2000

eds. R. Giacconi, S. Serio, and L. Stella

ISBN: 1-58381-071-4

Vol. CS-235 SCIENCE WITH THE ATACAMA LARGE MILLIMETER ARRAY (ALMA)

ed. Alwyn Wootten

ISBN: 1-58381-072-2

Vol. CS-236 ADVANCED SOLAR POLARIMETRY: THEORY, OBSERVATION, AND INSTRUMENTATION, The $20^{\text {th }}$ Sacramento Peak Summer Workshop ed. M. Sigwarth

ISBN: 1-58381-073-0

Vol. CS-237 GRAVITATIONAL LENSING: RECENT PROGRESS AND FUTURE GOALS eds. Tereasa G. Brainerd and Christopher S. Kochanek ISBN: 1-58381-074-9

Vol. CS-238 ASTRONOMICAL DATA ANALYSIS SOFTWARE AND SYSTEMS $X$ eds. F. R. Harnden, Jr., Francis A. Primini, and Harry E. Payne ISBN: $1-58381-075-7$

Vol. CS-239 MICROLENSING 2000: A NEW ERA OF MICROLENSING ASTROPHYSICS ed. John Menzies and Penny D. Sackett ISBN: $1-58381-076-5$

Vol. CS-240 GAS AND GALAXY EVOLUTION,

A Conference in Honor of the $20^{\text {th }}$ Anniversary of the VLA eds. J. E. Hibbard, M. P. Rupen, and J. H. van Gorkom ISBN: 1-58381-077-3

Vol. CS-241 CS-241 THE 7TH TAIPEI ASTROPHYSICS WORKSHOP ON COSMIC RAYS IN THE UNIVERSE

ed. Chung-Ming Ko

ISBN: $1-58381-079-X$

Vol. CS-242 ETA CARINAE AND OTHER MYSTERIOUS STARS:

THE HIDDEN OPPORTUNITIES OF EMISSION SPECTROSCOPY

eds. Theodore R. Gull, Sveneric Johannson, and Kris Davidson

ISBN: $1-58381-080-3$

Vol. CS-243 FROM DARKNESS TO LIGHT:

ORIGIN AND EVOLUTION OF YOUNG STELLAR CLUSTERS

eds. Thierry Montmerle and Philippe André

ISBN: $1-58381-081-1$

Vol. CS-244 YOUNG STARS NEAREARTH: PROGRESS AND PROSPECTS

eds. Ray Jayawardhana and Thomas P. Greene

ISBN: $1-58381-082-X$

Vol. CS-245 ASTROPHYSICAL AGES AND TIME SCALES

eds. Ted von Hippel, Chris Simpson, and Nadine Manset

ISBN: $1-58381-083-8$

Vol. CS-246 SMALL TELESCOPE ASTRONOMY ON GLOBAL SCALES, IAU Colloquium 183 eds. Wen-Ping Chen, Claudia Lemme, and Bohdan Paczyński ISBN: 1-58381-084-6 
PUBLISHED: 2001 ( ${ }^{*}$ asterisk means OUT OF STOCK)

Vol. CS-247 SPECTROSCOPIC CHALLENGES OF PHOTOIONIZED PLASMAS eds. Gary Ferland and Daniel Wolf Savin ISBN: $1-58381-085-4$

Vol. CS-248 MAGNETIC FIELDS ACROSS THE HERTZSPRUNG-RUSSELL DIAGRAM eds. G. Mathys, S. K. Solanki, and D. T. Wickramasinghe ISBN: $1-58381-088-9$

Vol. CS-249 THE CENTRAL KILOPARSEC OF STARBURSTS AND AGN: THE LA PALMA CONNECTION eds. J. H. Knapen, J. E. Beckman, I. Shlosman, and T. J. Mahoney ISBN: 1-58381-089-7

Vol. CS-250 PARTICLES AND FIELDS IN RADIO GALAXIES CONFERENCE eds. Robert $A$. Laing and Katherine M. Blundell ISBN: 1-58381-090-0

Vol. CS-251 NEW CENTURY OF X-RAY ASTRONOMY eds. $H$. Inoue and $H$. Kunieda ISBN: 1-58381-091-9

Vol: CS-252 HISTORICAL DEVELOPMENT OF MODERN COSMOLOGY eds. Vicent J. Martínez, Virginia Trimble, and María Jesús Pons-Borderia ISBN: 1-58381-092-7

PUBLISHED: 2002

Vol. CS-253

CHEMICAL ENRICHMENT OF INTRACLUSTER AND INTERGALACTIC MEDIUM eds. Roberto Fusco-Femiano and Francesca Matteucci ISBN: 1-58381-093-5

Vol. CS-254

EXTRAGALACTIC GAS AT LOW REDSHIFT eds. John S. Mulchaey and John T. Stocke ISBN: 1-58381-094-3

Vol. CS-255 MASS OUTFLOW IN ACTIVE GALACTIC NUCLEI: NEW PERSPECTIVES eds. D. M. Crenshaw, S. B. Kraemer, and I. M. George ISBN: 1-58381-095-1

Vol. CS-256 OBSERVATIONAL ASPECTS OF PULSATING B AND A STARS eds. Christiaan Sterken and Donald W. Kurtz ISBN: 1-58381-096-X

Vol. CS-257 AMIBA 2001: HIGH-Z CLUSTERS, MISSING BARYONS, AND CMB POLARIZATION eds. Lin-Wen Chen, Chung-Pei Ma, Kin-Wang Ng, and Ue-Li Pen ISBN: 1-58381-097-8

Vol. CS-258 ISSUES IN UNIFICATION OF ACTIVE GALACTIC NUCLEI eds. Roberto Maiolino, Alessandro Marconi, and Neil Nagar ISBN: 1-58381-098-6

Vol. CS-259 RADIAL AND NONRADIAL PULSATIONS AS PROBES OF STELLAR PHYSICS, IAU Colloquium 185 eds. Conny Aerts, Timothy R. Bedding, and Jørgen Christensen-Dalsgaard ISBN: 1-58381-099-4 


\section{ASP CONFERENCE SERIES VOLUMES}

Published by the Astronomical Society of the Pacific

PUBLISHED: 2002 (* asterisk means OUT OF STOCK)

Vol. CS-260 INTERACTING WINDS FROM MASSIVE STARS

eds. Anthony F. J. Moffat and Nicole St-Louis

ISBN: $1-58381-100-1$

Vol. CS-261 THE PHYSICS OF CATACLYSMIC VARIABLES AND RELATED OBJECTS

eds. B. T. Gänsicke, K. Beuermann, and K. Reinsch

ISBN: $1-58381-101-X$

Vol. CS-262 THE HIGH ENERGY UNIVERSE AT SHARP FOCUS: CHANDRA SCIENCE, held in conjunction with the $113^{\text {th }}$ Annual Meeting of the ASP eds. Eric M. Schlegel and Saeqa Dil Vrtilek

ISBN: $1-58381-102-8$

Vol. CS-263 STELLAR COLLISIONS, MERGERS AND THEIR CONSEQUENCES

ed. Michael M. Shara

ISBN: $1-58381-103-6$

Vol. CS-264 CONTINUING THE CHALLENGE OF EUV ASTRONOMY:

CURRENT ANALYSIS AND PROSPECTS FOR THE FUTURE

eds. Steve B. Howell, Jean Dupuis, Daniel Golombek,

Frederick M. Walter, and Jennifer Cullison

ISBN: 1-58381-104-4

Vol. CS-265 $\omega$ CENTAURI, A UNIQUE WINDOW INTO ASTROPHYSICS

eds. Floor van Leeuwen, Joanne D. Hughes, and Giampaolo Piotto

ISBN: 1-58381-105-2

Vol. CS-266 ASTRONOMICAL SITE EVALUATION IN THE VISIBLE AND RADIO RANGE,

IAU Technical Workshop

eds. J. Vernin, Z. Benkhaldoun, and C. Muñoz-Tuñón

ISBN: $1-58381-106-0$

Vol. CS-267* HOT STAR WORKSHOP III: THE EARLIEST STAGES OF MASSIVE STAR BIRTH ed. Paul A. Crowther ISBN: 1-58381-107-9

Vol. CS-268 TRACING COSMIC EVOLUTION WITH GALAXY CLUSTERS eds. Stefano Borgani, Marino Mezzetti, and Riccardo Valdarnini ISBN: $1-58381-108-7$

Vol. CS-269 THE EVOLVING SUN AND ITS INFLUENCE ON PLANETARY ENVIRONMENTS eds. Benjamín Montesinos, Álvaro Giménez, and Edward F. Guinan ISBN: 1-58381-109-5

Vol. CS-270 ASTRONOMICAL INSTRUMENTATION AND THE BIRTH AND GROWTH OF ASTROPHYSICS: A Symposium held in honor of Robert G. Tull eds. Frank N. Bash and Christopher Sneden ISBN: $1-58381-110-9$

Vol. CS-271 NEUTRON STARS IN SUPERNOVA REMNANTS eds. Patrick O. Slane and Bryan M. Gaensler ISBN: 1-58381-111-7

Vol. CS-272 THE FUTURE OF SOLAR SYSTEM EXPLORATION, 2003-2013 Community Contributions to the NRC Solar System Exploration Decadal Survey ed. Mark V. Sykes

ISBN: 1-58381-113-3 


\section{ASP CONFERENCE SERIES VOLUMES}

Published by the Astronomical Society of the Pacific

\section{PUBLISHED: 2002 ( ${ }^{*}$ asterisk means OUT OF STOCK)}

Vol. CS-273 THE DYNAMICS, STRUCTURE AND HISTORY OF GALAXIES eds. G. S. Da Costa and $H$. Jerjen ISBN: 1-58381-114-1

Vol. CS-274 OBSERVED HR DIAGRAMS AND STELLAR EVOLUTION eds. Thibault Lejeune and João Fernandes ISBN: $1-58381-116-8$

Vol. CS-275 DISKS OF GALAXIES: KINEMATICS, DYNAMICS AND PERTURBATIONS eds. E. Athanassoula, A. Bosma, and R. Mujica ISBN: 1-58381-117-6

Vol. CS-276 SEEING THROUGH THE DUST: THE DETECTION OF HI AND THE EXPLORATION OF THE ISM IN GALAXIES eds. A. R. Taylor, T. L. Landecker, and A. G. Willis ISBN: $1-58381-118-4$

Vol. CS 277 STELLAR CORONAE IN THE CHANDRA AND XMM-NEWTON ERA eds. Fabio Favata and Jeremy J. Drake ISBN: 1-58381-119-2

Vol. CS 278 NAIC-NRAO SCHOOL ON SINGLE-DISH ASTRONOMY: TECHNIQUES AND APPLICATIONS eds. Snezana Stanimirovic, Daniel Altschuler, Paul Goldsmith, and Chris Salter ISBN: 1-58381-120-6

Vol. CS 279 EXOTIC STARS AS CHALLENGES TO EVOLUTION, IAU Colloquium 187 eds. Christopher A. Tout and Walter Van Hamme ISBN: 1-58381-122-2

Vol. CS 280 NEXT GENERATION WIDE-FIELD MULTI-OBJECT SPECTROSCOPY eds. Michael J. I. Brown and Arjun Dey ISBN: 1-58381-123-0

Vol. CS 281 ASTRONOMICAL DATA ANALYSIS SOFTWARE AND SYSTEM XI eds. David A. Bohlender, Daniel Durand, and Thomas H. Handley ISBN: $1-58381-124-9$ ISSN: $1080-7926$

Vol. CS 282 GALAXIES: THE THIRD DIMENSION eds. Margarita Rosado, Luc Binette, and Lorena Arias ISBN: 1-58381-125-7

Vol. CS 283 A NEW ERA IN COSMOLOGY eds. Nigel Metcalfe and Tom Shanks ISBN: $1-58381-126-5$

Vol. CS 284 AGN SURVEYS eds. R. F. Green, E. Ye. Khachikian, and D. B. Sanders ISBN: $1-58381-127-3$

Vol. CS 285 MODES OF STAR FORMATION AND THE ORIGIN OF FIELD POPULATIONS eds. Eva K. Grebel and Walfgang Brandner ISBN: 1-58381-128-1 
PUBLISHED: 2003 (" asterisk means OUT OF STOCK)

Vol. CS 286

Vol. CS 287

Vol. CS 288

Vol. CS 289

Vol. CS 290

Vol. CS-291

Vol. CS-292

Vol. CS-293

Vol. CS-294

Vol. CS-295

Vol. CS-296

Vol. CS-297

Vol. CS-298
CURRENT THEORETICAL MODESL AND HIGH RESOLUTION SOLAR OBSERVATIONS: PREPARING FOR ATST eds. Alexei A. Pevtsov and Han Uitenbroek ISBN: $1-58381-129-X$

GALACTIC STAR FORMATION ACROSS THE STELLAR MASS SPECTRUM eds. J.M. De Buizer and N.S. van der Bliek ISBN:1-58381-130-3

STELLAR ATMOSPHERE MODELING eds. I. Hubeny, D. Mihalas and K. Werner ISBN: 1-58381-131-1

THE PROCEEDINGS OF THE IAU $8^{\text {TH }}$ ASIAN-PACIFIC REGIONAL MEETING, VOLUME 1 eds. Satoru Ikeuchi, John Hearnshaw and Tomoyuki Hanawa ISBN: 1-58381-134-6

ACTIVE GALACTIC NUCLEI: FROM CENTRAL ENGINE TO HOST GALAXY eds. S. Collin, F. Combes and I. Shlosman

ISBN: $1-58381-135-4$

HUBBLE'S SCIENCE LEGACY:

FUTURE OPTICAL/ULTRAVIOLET ASTRONOMY FROM SPACE eds. Kenneth R. Sembach, J. Chris Blades, Garth D. Illingworth and Robert C. Kennicutt, Jr.

ISBN: $1-58381-136-2$

INTERPLAY OF PERIODIC, CYCLIC AND STOCHASTIC VARIABILITY IN SELECTED AREAS OF THE H-R DIAGRAM

ed. Christiaan Sterken

ISBN: $1-58381-138-9$

3D STELLAR EVOLUTION

eds. S. Turcotte, S. C. Keller and R. M. Cavallo

ISBN: 1-58381-140-0

SCIENTIFIC FRONTIERS IN RESEARCH ON EXTRASOLAR PLANETS

eds. Drake Deming and Sara Seager

ISBN: 1-58381-141-9

ASTRONOMICAL DATA ANALYSIS SOFTWARE AND SYSTEMS XII eds. Harry E. Payne, Robert I. Jedrzejewski and Richard N. Hook ISBN: $1-58381-142-7$

NEW HORIZONS IN GLOBULAR CLUSTER ASTRONOMY eds. Giampaolo Piotto, Georges Meylan, S. George Djorgovski and Marco Riello ISBN: 1-58381-143-5

STAR FORMATION THROUGH TIME, A Conference to Honour Robert J. Terlevich eds. Enrique Pérez, Rosa M. González Delgado and Guillermo Tenorio-Tagle ISBN: $1-58381-144-3$

GAIA SPECTROSCOPY: SCIENCE AND TECHNOLOGY

ed. Ulisse Munari

ISBN: 1-58381-145-1 


\section{ASP CONFERENCE SERIES VOLUMES}

Published by the Astronomical Society of the Pacific

\section{PUBLISHED: 2003 ( ${ }^{*}$ asterisk means OUT OF STOCK)}

Vol. CS-299 HIGH ENERGY BLAZAR ASTRONOMY, An International Conference held to Celebrate the $50^{\text {th }}$ Anniversary of Tuorla Observatory eds. Leo O. Takalo and Esko Valtaoja ISBN: 1-58381-146-X

Vol. CS-300 RADIO ASTRONOMY AT THE FRINGE, A Conference held in honor of Kenneth I. Kellermann, on the occasion of his $65^{\text {th }}$ Birthday eds. J. Anton Zensus, Marshall H. Cohen and Eduardo Ros ISBN: $1-58381-147-8$

Vol. CS-301 MATTER AND ENERGY IN CLUSTERS OF GALAXIES eds. Stuart Bowyer and Chorng-Yuan Hwang ISBN: $1-58381-149-4$

Vol. CS-302 RADIO PULSARS, In celebration of the contributions of Andrew Lyne, Dick Manchester and Joe Taylor - A Festschrift honoring their $60^{\text {th }}$ Birthdays eds. Matthew Bailes, David J. Nice and Stephen E. Thorsett ISBN: 1-58381-151-6

Vol. CS-303

SYMBIOTIC STARS PROBING STELLAR EVOLUTION eds. R. L. M. Corradi, J. Mikołajewska and T. J. Mahoney ISBN: $1-58381-152-4$

Vol. CS-304

CNO IN THE UNIVERSE

eds. Corinne Charbonnel, Daniel Schaerer and Georges Meynet ISBN: 1-58381-153-2

Vol. CS-305 International Conference on MAGNETIC FIELDS IN O, B AND A STARS: ORIGIN AND CONNECTION TO PULSATION, ROTATION AND MASS LOSS eds. Luis A. Balona, Huib F. Henrichs and Rodney Medupe ISBN: $1-58381-154-0$

Vol. CS-306 NEW TECHNOLOGIES IN VLBI

ed. Y. C. Minh

ISBN: $1-58381-155-9$

Vol. CS-307 SOLAR POLARIZATION 3 eds. Javier Trujillo Bueno and Jorge Sanchez Almeida ISBN: $1-58381-156-7$

Vol. CS-308 FROM X-RAY BINARIES TO GAMMA-RAY BURSTS

eds. Edward P. J. van den Heuvel, Lex Kaper, Evert Rol and Ralph A. M. J. Wijers ISBN: $1-58381-158-3$

PUBLISHED: 2004

Vol. CS-309 ASTROPHYSICS OF DUST eds. Adolf N. Witt, Geoffrey C. Clayton and Bruce T. Draine ISBN: 1-58381-159-1

Vol. CS-310 VARIABLE STARS IN THE LOCAL GROUP, IAU Colloquium 193 eds. Donald W. Kurtz and Karen R. Pollard ISBN: 1-58381-162-1 
PUBLISHED: 1999 ( ${ }^{*}$ asterisk means OUT OF STOCK)

Vol. No. 190 NEW VIEWS OF THE MAGELLANIC CLOUDS

eds. You-Hua Chu, Nicholas B. Suntzeff, James E. Hesser. and David A. Bohlender

ISBN: 1-58381-021-8

Vol. No. 191

ASYMPTOTIC GIANT BRANCH STARS

eds. T. Le Bertre, A. Lèbre, and C. Waelkens

ISBN: 1-886733-90-2

Vol. No. 192

THE STELLAR CONTENT OF LOCAL GROUP GALAXIES

eds. Patricia Whitelock and Russell Cannon

ISBN: 1-886733-82-1

Vol. No. 193

WOLF-RAYET PHENOMENA IN MASSIVE STARS AND STARBURST GALAXIES eds. Karel A. van der Hucht, Gloria Koenigsberger, and Philippe R. J. Eenens ISBN: 1-58381-004-8

Vol. No. 194 ACTIVE GALACTIC NUCLEI AND RELATED PHENOMENA

eds. Yervant Terzian, Daniel Weedman, and Edward Khachikian

ISBN: $1-58381-008-0$

PUBLISHED: 2000

Vol. XXIVA

TRANSACTIONS OF THE INTERNATIONAL ASTRONOMICAL UNION REPORTS ON ASTRONOMY 1996-1999

ed. Johannes Andersen

ISBN: 1-58381-035-8

Vol. No. 195 HIGHLY ENERGETIC PHYSICAL PROCESSES AND MECHANISMS FOR EMISSION FROM ASTROPHYSICAL PLASMAS eds. P. C. H. Martens, S. Tsuruta, and M. A. Weber ISBN: 1-58381-038-2

Vol. No. $197^{*} \quad$ ASTROCHEMISTRY: FROM MOLECULAR CLOUDS TO PLANETARY SYSTEMS eds. Y. C. Minh and E. F. van Dishoeck ISBN: 1-58381-034-X

Vol. No. 198 THE LIGHT ELEMENTS AND THEIR EVOLUTION eds. L. da Silva, M. Spite, and J. R. de Medeiros ISBN: 1-58381-048-X

PUBLISHED: 2001

IAU SPS ASTRONOMY FOR DEVELOPING COUNTRIES

Special Session of the XXIV General Assembly of the IAU ed. Alan H. Batten

ISBN: 1-58381-067-6

Vol. No. 196

PRESERVING THE ASTRONOMICAL SKY eds. R. J. Cohen and W. T. Sullivan, III ISBN: 1-58381-078-1

Vol. No. 200 * THE FORMATION OF BINARY STARS eds. Hans Zinnecker and Robert D. Mathieu ISBN: 1-58381-068-4

Vol. No. 203

RECENT INSIGHTS INTO THE PHYSICS OF THE SUN AND HELIOSPHERE: HIGHLIGHTS FROM SOHO AND OTHER SPACE MISSIONS eds. Pål Brekke, Bernhard Fleck, and Joseph B. Gurman ISBN: 1-58381-069-2 
PUBLISHED: 2001 ( ${ }^{*}$ asterisk means OUT OF STOCK)

Vol. No. 204 THE EXTRAGALACTIC INFRARED BACKGROUND AND ITS COSMOLOGICAL IMPLICATIONS

eds. Martin Harwit and Michael G. Hauser

ISBN: 1-58381-062-5

Vol. No. 205

GALAXIES AND THEIR CONSTITUENTS

AT THE HIGHEST ANGULAR RESOLUTIONS

eds. Richard T. Schilizzi, Stuart N. Vogel, Francesco Paresce, and Martin S. Elvis ISBN: 1-58381-066-8

Vol. XXIVB TRANSACTIONS OF THE INTERNATIONAL ASTRONOMICAL UNION REPORTS ON ASTRONOMY

ed. Hans Rickman

ISBN: 1-58381-087-0

PUBLISHED: 2002

Vol. No. 12

HIGHLIGHTS OF ASTRONOMY

ed. Hans Rickman

ISBN: 1-58381-086-2

Vol. No. 199

THE UNIVERSE AT LOW RADIO FREQUENCIES

eds. A. Pramesh Rao, G. Swarup, and Gopal-Krishna

ISBN: $58381-121-4$

Vol. No. 206

COSMIC MASERS: FROM PROTOSTARS TO BLACKHOLES

eds. Victor Migenes and Mark J. Reid

ISBN: 1-58381-112-5

Vol. No. 207

EXTRAGALACTIC STAR CLUSTERS

eds. Doug Geisler, Eva K. Grebel, and Dante Minnit

ISBN: $1-58381-115-X$

PUBLISHED: 2003

Vol. XXVA

TRANSACTIONS OF THE INTERNATIONAL ASTRONOMICAL UNION REPORTS ON ASTRONOMY 1999-2002

ed. Hans Rickman

ISBN: $1-58381-137-0$

Vol. No. 208 ASTROPHYSICAL SUPERCOMPUTING USING PARTICLE SIMULATIONS eds. Junichiro Makino and Piet Hut

ISBN: 1-58381-139-7

Vol. No. 209 PLANETARY NEBULAE: THEIR EVOLUTION AND ROLE IN THE UNIVERSE eds. Sun Kwok, Michael Dopita and Ralph Sutherland ISBN: $1-58381-148-6$

Vol. No. 210 MODELLING OF STELLAR ATMOSPHERES

eds. N. Piskunov, W. W. Weiss and D. F. Gray

ISBN: $1-58381-160-5$

Vol. No. 211

BROWN DWARFS

ed. Eduardo Martin

ISBN: $1-58381-132-X$

Vol. No. 212 A MASSIVE STAR ODYSSEY: FROM MAIN SEQUENCE TO SUPERNOVA eds. Karel A. van der Hucht, Artemio Herrero and César Esteban ISBN: $1-58381-133-8$ 
INTERNATIONAL ASTRONOMICAL UNION (IAU) VOLUMES

Published by the Astronomical Society of the Pacific

PUBLISHED: 2003 ( ${ }^{*}$ asterisk means OUT OF STOCK)

Vol. No. 214 HIGH ENERGY PROCESSES AND PHENOMENA IN ASTROPHYSICS eds. X. D. Li, V. Trimble and Z. R. Wang

ISBN: 1-58381-157-5

PUBLISHED: 2004

Vol. No. 219 STARS AS SUNS: ACTIVITY, EVOLUTION AND PLANETS eds. A. K. Dupree and A. O. Benz ISBN: $1-58381-163-X$

Vol. No. 221 STAR FORMATION AT HIGH ANGULAR RESOLUTION eds. Michael Burton, Ray Jayawardhana and Tyler Bourke ISBN: 1-58381-161-3

Ordering information is available at the beginning of the listing 


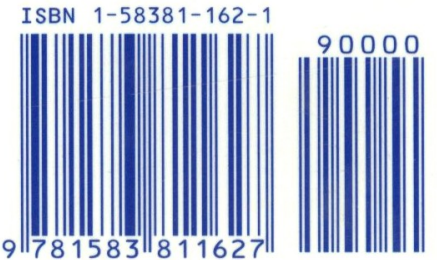

